\title{
REMONTANDO EL 32 La memoria histórica contra el archivo
}

Rafael Lara-Martínez

[La memoria histórica] tiene por vocación silenciosa borrar el archivo y empujarnos a la amnesia. J. Derrida

\section{Resumen}

"Remotando el 32. La memoria histórica contra el archivo" analiza el papel que desempeña el escritor salvadoreño Salarrué (1899-1975) - y los círculos de artistas teósofos - durante el año clave de 1932. El siglo XXI rescata la imagen del autor como prototipo de la denuncia de una represión desmesurada que organiza el régimen del general Maximiliano Hernández Martínez (1931-1934; 1935-1939; 1939-1944) contra una revuelta ocurrida en enero de ese año. Para tal efecto, la ley de la memoria histórica suprime casi toda la documentación primaria de ese año clave. La argumentación cimienta su tesis en una sola publicación del autor eliminando el amplio archivo histórico que haría del artista un colaborador solapado del régimen. El artículo restituye el registro borrado adrede por una historiografía ansiosa de olvidar.

Palabras claves: Círculo de artistas, memoria histórica, represión, dictadura de Martínez

\begin{abstract}
"Remoting 1932. Historical Memory against the Archive" analyzes the role that plays the Salvadoran writer Salarrue (1899-1975) during the key year of 1932. In the 21 th century, the author symbolizes the emblem of an engaged writer denouncing the atrocities of the regime commanded by General Maximiliano Hernández Martínez (1931-1934; 1935-1939; 1939-1944) against a popular revolt in January 1932. For such a matter, the law of historical memory suppresses almost all-primary documentation of that key date. The current argument founds its thesis in only one of the author's publications, erasing the ample archive, which would transform him into a cunning collaborator of Martinez's regime. The article restitutes the file obliterated in purpose by a historical memory anxious of oblivion.
\end{abstract}

Keywords: Circle of artists, Historical Memories, Repression, Martinez Dictatorship

U na hipótesis esencial del filósofo francés Jacques Derrida contrapone la memoria histórica al archivo. Cuando el legado cultural de un país remite a un pasado trágico y borroso - a un "archivo del mal" - un "mal de archivo" impone el olvido. La historiografía tiende a ocultar cierta documentación primaria para reinventar el pasado en el presente. Esta omisión es el caso de la historia intelectual salvadoreña hacia el inicio del siglo XXI. En particular, la omisión de un amplio archivo artístico-literario afecta el despegue de la presidencia del general Maximiliano Hernández Martínez (19311934; 1935-1939; 1939-1944). De aplicar 
la hipótesis derridiana a los estudios salvadoreños, la razón sería obvia. "El mal de archivo" marca la huella del "archivo del mal" bajo tachadura (sous rature). La condena que el siglo XXI ejerce sobre un régimen militar y represivo se traduce en la supresión de sus registros culturales.

Tal borrón lo demuestra la siguiente lista de revistas jamás citada en los trabajos académicos especializados sobre el martinato, a saber: A. B. C. (1932), Ahora (1938-1951), Amatl. Correo del Maestro (1939), Antena (1934), Ateneo. Revista del Ateneo de El Salvador (19121933; 1940-1958), Boletín de la Biblioteca Nacional (1932-1946), Boletín de la Policía Nacional (1932), Boletín Estadístico (1934), Cypactly, Revista de Variedades (19331952), Dharma. Órgano de la Sociedad Teosófica Teotl (noviembre de 19321941; Cypactly (No. 14, 15 de abril de 1932); establece un vínculo directo entre el director de la revista y de la Logia, Rafael Heredia Reyes, y la diplomacia del régimen del general Martínez, miembro de la Logia), Diario Nuevo (1933-1944), Guión (1938), Hermes. Revista de Ciencias (1934-1937), La República, Suplemento del Diario Oficial (1932-1944), Repertorio Americano, Revista del Banco Central de Reserva (1934-), Revista del Círculo Militar (1935-1938), Revista del Departamento de Historia (1938-1940), Revista El Salvador. Órgano Oficial de la Junta Nacional de Turismo (1935-1939), Atlahunka, Revista del Ministerio de Instrucción Pública (19411944), Revista Mensual Ilustrada (19361939), Tzunpame (1941-1948), Vivir (1932; dirigida por Alberto Guerra Trigueros, director de Patria e ilustrada por Cáceres Madrid, "fiel retrato de nuestra sociedad en "él [= Patria] hay patriotas"), etc.

Este listado parcial se halla ausente, casi en su integridad, en los trabajos académicos más autorizados sobre el tema (véanse:
Alvarenga, 1996; Gould y Lauria-Santiago, 2008; Lindo, Ching y Lara-Martínez, 2007, Pérez-Brignoli, 2001, Roque Baldovinos, 1999 y Tilley, 2005). La razón derridiana del "mal de archivo" la explica la colaboración de los intelectuales con el régimen del general Martínez. La memoria histórica en boga recuerda su presidencia por la represión despiadada contra un levantamiento campesino ocurrido en el occidente de El Salvador, a principios de 1932.

En particular, la investigación histórica se centra en elucidar la organización social de la revuelta y las razones de la reprimenda militar. Aún no existen estudios exhaustivos que indaguen la relación del intelectual salvadoreño con el poder martinista. La tónica del comentario señala una neta contradicción entre la memoria y el archivo nacional olvidado. Mientras la historia social considera que un escritor indigenista como Miguel Ángel Espino constituiría uno de los pilares "ideológicos [...] para apoyar las peticiones indígenas" (Gould y Lauria-Santiago, 2008: 52-53), el Diario Oficial lo describe como funcionario del régimen quien defiende la represión en nombre de la soberanía nacional y del anti-imperialismo en México y en Guatemala (Diario Oficial, 9 de febrero, 12 de septiembre y 21 de noviembre de 1932).

La paradoja resulta flagrante, ya que la lectura de la obra espiniana urge a fundar un indigenismo americanista autónomo, a la vez que en su cargo como miembro del servicio diplomático - "Secretario y Encargado de los Archivos de la Legación de El Salvador en Guatemala" y "Jefe de la Sección Diplomática de Relaciones Exteriores" - defiende la acción armada del régimen martinista (Diario Oficial, fechas citadas de 1932). Además, su padre -el poeta Alfonso Espino- es colega del general Martínez en el Ateneo 
de El Salvador y Secretario Privado de la Presidencia (Diario Oficial, 22 de diciembre de 1931).

Otro ejemplo notable es el del mejor escritor salvadoreño de la primera mitad del siglo XX: Salarrué (1899-1975). La única obra que suele citarse en los trabajos históricos se intitula "Mi respuesta a los patriotas" (Repertorio Americano, 27 de febrero de 1932). A lo sumo se agrega Catleya luna (1974) cuya novela incrustada, "Balsamera", narra la epopeya de los Izalco y su represión desmesurada. $\mathrm{Mi}$ experiencia de conferencista en El Salvador me enseña que la "respuesta" es el escrito más popularizado entre el público general y universitario. El auditorio siempre lo cita en prueba contundente de la distancia del autor con el general Martínez y en denuncia de la "matanza".

No obstante, ni Salarrué emplea el término de "matanza", ni su escrito ofende a los intelectuales martinistas de la época. Basta recordar que el propio redactor de Dharma. Órgano de la Sociedad Teosófica Teotl, Juan Felipe Toruño, no interpreta la "respuesta" de su colega Salarrué como una denuncia ("Actividades literarias en el año de 1932", Revista del Ateneo, no. 145, 1932 y Boletín de la Biblioteca Nacional, Nos. 12-13, enero de 1934: 51-55). Es cierto que Salarrué se aparta de "los patriotas" y de los "capitalistas"; pero a la vez acusa a "los comunistas" - a los insurrectos - de imponer "la justicia" al "degollar" a sus enemigos. Por esta razón, sus colegas lo leen de manera muy distinta al público salvadoreño actual.

El conocimiento generalizado de la "respuesta" de Salarrué sirve para ocultar todas las demás "actividades literarias" y públicas del autor en 1932. Un ejemplo adicional sienta la pauta final antes de revelarlas. Para Roque Baldovinos (1999), el "Cuento de barro. La botija" testimonia de la defensa de los valores indígenas tradicionales. Sin embargo, el estudioso no menciona que el relato lo publica y lo elogia la revista gubernamental Boletín de la Biblioteca Nacional en 1932, como si las esferas oficiales del martinato criticaran su propia labor anti-indigenista estatal. A semejanza del caso de Espino, habría en Salarrué una ausencia de los archivos nacionales de la época que validan afirmaciones contradictorias.

No en vano, el mismo Roque Baldovinos juzga el cuento de barro "El espantajo" -incluido tardíamente en Trasmallo (1954) - como prueba de la denuncia de la matanza de 1932 (véase también: Ramírez, 1977). Pero, de nuevo, una parte esencial del archivo de Salarrué queda suprimido. Hacia los años cincuenta, el artista ocupa cargos oficiales en el Ministerio de Relaciones Exteriores de los gobiernos del coronel Óscar Osorio (1950-1956) y de José María Lemus (1956-1960), a quienes defiende en una carta pública (La Prensa Gráfica, 15 de diciembre de 1955). Hay que "colaborar con uno de los mejores gobiernos que ha tenido El Salvador en toda su historia [...] la verdadera vanguardia del país" sin la cual 1932 pasa al olvido. Además, unos veinte años antes, en 1938, "el espantajo" más original lo diseña Salarrué en la "Escuela de Varones de la Colonia América" en honor al hijo del general Martínez, al igual que a la reforma educativa del régimen (Revista del Ministerio de Instrucción Pública, No, 3-4, julio-diciembre de 1942). Antes que represión militar contra el indígena en 1932, hacia finales del martinato, "el espantajo" representa "el fantasma de la escuela vieja - tristeza y tortura - destruido por el aliento vital - alegría y amor de la nueva escuela". 
Ante tales omisiones documentales y paradojas flagrantes, a continuación se descubren algunas fuentes primarias jamás citadas en los trabajos sobre el período martinista. Estas revistas culturales no sólo declaran el apoyo de los intelectuales salvadoreños más connotados a su régimen. También exponen la defensa de la represión en nombre de la soberanía nacional, del anti-imperialismo e, incluso, del pacifismo "comunista". Tal es el "archivo del mal" que en el siglo XXI provoca un "mal de archivo", oculto por la historiografía literaria hasta el 2014.

\section{I.}

En diciembre de 1931, el ascenso de Maximiliano Hernández Martínez lo apoyan casi todos los intelectuales antiimperialistas de Centroamérica (Repertorio Americano, 21 de diciembre de 1931). El primer escritor quecondena de "matanza de El Salvador" en público - el costarricense Octavio Jiménez Alpízar (Juan del Camino) en el Repertorio Americano (30 de enero y 13 de febrero de 1932) - un mes antes califica el golpe de estado de "ejemplo viril" contra el imperialismo estadounidense. Entre diciembre de 1931 y enero-febrero de 1932, Jiménez Alpízar oscila de considerar al general Martínez como fuerza política contra el "tutelaje" estadounidense, hasta incriminarlo por "la matanza". Un giro tan radical aún no se documenta para los intelectuales salvadoreños, quienes jamás emplean ese término de manera explícita en sus publicaciones, nacionales ni extranjeras.

Igualmente, en una revista de teósofos independientes, Cypactly. Tribuna del Pensamiento Libre de América, la foto que certifica al general Martínez como "presidente constitucional de El Salvador" se conjuga con el "Cuento de barro.
Benjasmín" de Salarrué, ilustrado por Luis Alfredo Cáceres Madrid, en una unidad indisoluble entre el letrado y el soldado (Cypactly, 8 de diciembre de 1931; junto a otros diez cuentos de barro, "Benjasmín" no se incluye en el libro de 1933 ni en la Narrativa completa de 1999). A la vez, entre los círculos universitarios cercanos al radical periódico Opinión estudiantil, "esta nueva época" significa "momentos de rebeldías libertarias [...] a la obra de la regeneración maravillosamente generada la noche del dos de diciembre [día del golpe de estado, en el cual renacen] las libertades ciudadanas tiránicamente en cadenas" (Augusto Antonio Villalta, en Cypactly, $1^{\circ}$ de enero de 1932).

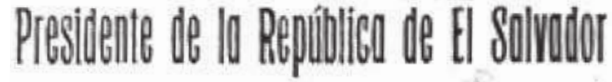

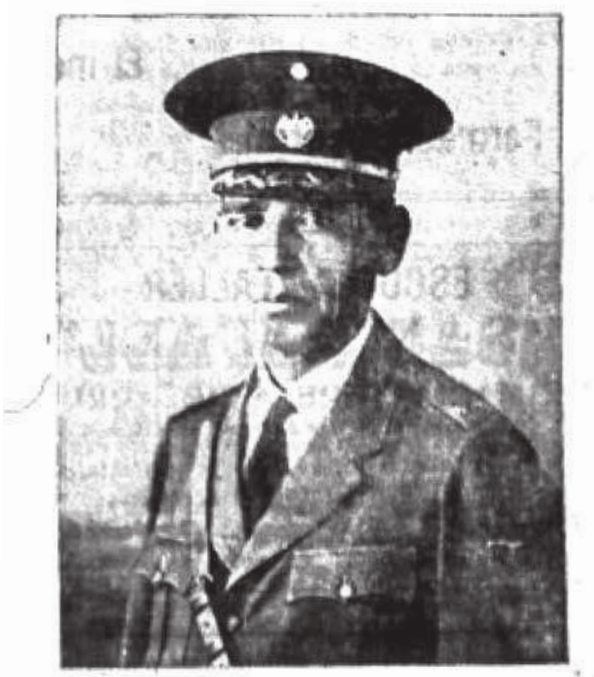

General Max. Hernández Martinez,

PRESIDENTE DE LA REPÚBLICA DE EL SALVADOR

General Max. Hernández Martínez, Quien a raíz del levantamiento del dos de Diciembre corriente, fue llamado por el Directorio Militar a fin de tomarle la protesta de ley para que ejerza la Primera Magistratura de la Nación Salvadoreña, por corresponderle a él en su concepto de Vicepresidente. Cargo que esperamos sabrá llevar por buen derrotero sin ir al fracaso como su antecesor, que no supo comprender las aspiraciones del pueblo salvadoreño que había confiado en él, causando descontento general que dio margen a su caída. 
El máximo oponente salvadoreño de la matanza, Alberto Masferrer, secunda las motivaciones de los círculos teosóficos por apoyar al general Martínez de manera indirecta. En nombre del antiimperialismo, no sólo Masferrer convoca la destitución del presidente Araujo quien invita a EEUU a intervenir para restituirlo - también aprueba al nuevo mandatario (Masferrer, "Contra el expresidente Araujo", 6 y 10 de diciembre de 1931). Si Araujo "pone en manos del gobierno de Washington la solución del conflicto que ha estallado entre él y el pueblo salvadoreño", Masferrer favorece la destitución del presidente electo por el Directorio Militar, junto a sus colegas Serafín Quiteño y Adolfo Pérez M. Dos días antes que Cypactly endose al general Martínez, el maestro declara su fidelidad anti-imperialista. "Sean quienes fueren los que han asumido el poder en El Salvador, nosotros los aceptamos desde ahora, y les prestamos nuestra adhesión, por habernos desembarazado de un hombre que con tanta facilidad acude a la intervención de un poder extraño, que ningún derecho tiene para dirimir nuestras contiendas". La hoja suelta que circula en Guatemala la publica el Diario Latino cuatro días después, el 10 de diciembre, cuya lectura motiva a los grupos masferrerianos a proseguir el ejemplo de colaboración de los teósofos con el nuevo régimen. Dada la importancia de este documento olvidado, se reproduce en un apéndice.

En enero de 1933, un criterio político semejante lo declara el socialista Vicente Sáenz en México. Según este otro costarricense, todos los intelectuales salvadoreños respaldan la política antiimperialista de su presidente, el general Martínez, quien representa el eslabón más fuerte para "romper las cadenas, las del imperialismo yanqui en Centroamérica". La retórica anti-imperialista opaca la conmemoración de la matanza en enero de 1933, fecha de la visita de Sáenz a El Salvador y de su entrevista al general Martínez y a sus colegas salvadoreños.

El silencio de la matanza lo certifica la chilena Gabriela Mistral en su único artículo sobre El Salvador, publicado originalmente en Chile y en Costa Rica (Repertorio Americano y La República, 1933). Desde Italia, la futura premio nobel recuerda el sabroso café salvadoreño que prueba en septiembre de 1931, durante una apoteosis del indigenismo nacional financiada tardíamente por el general Martínez (Diario Oficial, 23 de junio de 1933). Una foto célebre - publicada en el Repertorio Americano- consigna la amistad intelectual de la chilena con Salarrué y con el nicaragüense Adolfo Ortega Díaz (octubre de 1931; la chilena introduce varios cuentos de barro de Salarrué al público costarricense). Menos conocida es la amistad que Mistral entabla con otros artistas salvadoreños. La revista que reúne a los literatos teósofos, Cypactly, le dedica un número, ilustrado en su portada por Luis Alfredo Cáceres Madrid, uno de los fundadores del indigenismo nacional y promotor de esta ideología en el ejército (Cypactly, $1^{\circ}$ de octubre de 1931). La misma red de intelectuales que, junto a Mistral, festeja la autonomía cultural es aquella cuyo nacionalismo fundará una idea de nación durante el martinato. Existe una neta dislocación del indigenismo letrado y la revuelta indígena, según habrá de verse, por el apoyo artístico al general Martínez. 


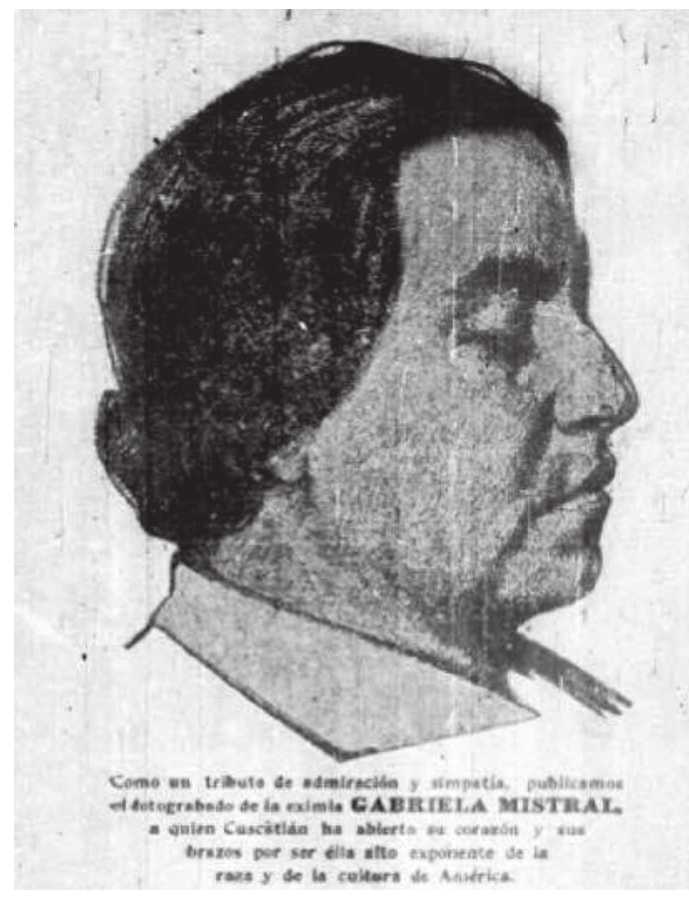

Grabado "elaborado con exquisito arte por nuestro colaborador y sincero amigo Luis Alfredo Cáceres Madrid" (Cypactly. Tribuna del Pensamiento Libre de América, $1^{\circ}$ de ocubre de 1931).

Pero no sólo el imperialismo yanqui acecha el istmo, ya que "el oso ruso" - según el decir sandinista de Gustavo Alemán Bolaños (1944) - también promueve un "levantamiento de venganza" (Salarrué, "Cuento de barro. Balsamera", Repertorio Americano, 1935). Por tal asedio "vengativo", en México, el indigenismo de Miguel Ángel Espino defiende la legítima defensa contra el imperialismo soviético que asalta la nación salvadoreña, mientras el futuro marxista Alejandro Dagoberto Marroquín trabaja en la Gobernación del Departamento de La Libertad por Decreto Ejecutivo (Diario Oficial, 9 de febrero, 12 de septiembre y 9 de noviembre de 1932 para Espino y 25 de febrero de 1932 para Marroquín). Ambos escritores la actualidad los evalúa como un antimartinista en la "resistencia pasiva" el primero por su novela Hombres contra la muerte (1942; véase: Alvarenga, 2007) y acérrimo oponente por su marxismo científico el segundo. Pero se olvida que hasta la segunda mitad del segundo mandato, como intelectual de prestigio, en la Universidad de El Salvador, el general Martínez alterna junto "a dos alumnos de la Facultad de Jurisprudencia y Ciencias Sociales" de los quienes destaca "Alejandro Dagoberto Marroquín" (La Universidad, No. 2, 1937)

Los llamados primeros poetas comunistas - "poetas del 32" como Pedro Geoffroy Rivas y Gilberto González y Contreras publican poemas de amor en las revistas oficiales y trabajan para la censura de prensa del régimen. Se hallan más interesados en el cuerpo femenino que en la matanza (Boletín de la Biblioteca Nacional, 1932). Si a Geoffroy Rivas le preocupa el "sexo" con una "mujer blanca", González y Contreras elogia la libertad del jazz mientras ejerce su cargo de "censor de prensa" (Boletín de la Biblioteca Nacional, 10 de septiembre de 1932).

Ante la doble amenaza imperialista estadounidense y soviética - la "respuesta" de Salarrué propone un cometido dual de represión y de amor - en metáfora de la autoridad familiar. Es necesario el castigo del Padre, el del estado, y el consuelo de la Madre, el de la nación. Según la alegoría salarrueriana, el Padre, el estado, reprime; la Madre, la nación, conforta ("Los que no entendemos. El sentido común", sin fecha ni editorial, cortesía de Ricardo Aguilar). En 1932, para las redes intelectuales teosóficas y la iglesia católica, la sanción paterna justifica la matanza en legítima defensa por la soberanía nacional, según lo confirman las dos citas siguientes, al igual que la "misa en el portón de la catedral" - ofrecida por el Arzobispo- 
para "bendecir al Gobierno, Cuerpo del Ejército, Guardia Nacional, Guardia Cívica y Cuerpo de Policía General, por su noble y patriótica actitud en defensa de la sociedad salvadoreña, de las instituciones patrias y de la autonomía nacional" (El Día, 25 de febrero de 1932 y Diario Latino, 29 de febrero de 1932).

“Matan a sangre fría [...] los peores asesinos. Por eso merecen condena eterna todos los hechos sangrientos hace algunos meses ejecutados por forajidos [...] es una dolorosa equivocación creer que el comunismo se practica segando vidas $\mathrm{y}$ arrasando propiedades. Esas doctrinas que tuvieron origen en el Sermón de la montaña, no son de destrucción sino de conservación [...] Esto lo han ignorado [...] nuestros campesinos por eso han delinquido [...] y se dejaron llevar al sacrificio de su vida" (Eugenio Cuéllar cuyo cuento lo ilustra Pedro García V., quien diseña varios "cuentos de barro". Cypactly, No. 17, 22 de junio de 1932; la relación de Cuéllar con Salarrué queda a determinar, aun si su enlace visual resulta obvia en 1932 por el ilustrador común de sus escritos).

Quienes deciden "lanzarse a desantentadas rebeldías obedeciendo azuzamientos subversivos [de los comunistas] sólo les dejan saldos de miseria y muerte" (Cypactly, No. 19, 31 de julio de 1932; juicio anónimo editorial de la revista).

El acto represivo del padre lo subsana la Mater Dolorosa. El alivio materno se intitula "La hora de los maestros" (Salvador Cañas, Cypactly, 28 de febrero de 1932). Suprimida la amenaza comunista - la "ola roja" de violencia en la "selva roja" - hay que forjar patria (véase: Machón Vilanova, 1948 y Salarrué. "Selva roja" es el título original de Catleya luna (1974) hasta mediados de los sesenta; se trata de una novela tardía sobre 1932 en la cual los críticos confunden la fecha en la novela (1932) con la fecha de la novela (1964-1974). Al hablar de los pipiles, Salarrué mezcla las divinidades mexicas con las salvadoreñas; el náhuatl-mexicano del altiplano se revierte al náhuat-pipil del trópico según se justifica en la conclusión).

"Fue preciso que la tragedia surgiera, para que supiéramos [...] los hombres de letras [...] sugerir ideales" de identidad nacional (Cañas, Cypactly, 28 de febrero de 1932). Tal labor de la "política de la cultura" es "la obligación del "intelectual en el amplio sentido de la palabra" (Quino Caso, Boletín de la Biblioteca Nacional, 1932). El compromiso letrado al que urge Cañas sella el vínculo entre el intelectual y el poder.

En 1932, ese artista por excelencia se llama Salarrué. Sus "cuentos de barro" los reproducen las publicaciones oficiales en muestra de una "política de la cultura". Esta nueva "política del espíritu" se organiza alrededor de las revistas oficiales como el Boletín de la Biblioteca Nacional. Según el ultra-martinista Julio C. Escobar - Director de la Biblioteca y de la revista - "auspiciada por el Señor Presidente de la República, general Max. H. Martínez, y a iniciativa del Ateneo [y de] un espíritu dilecto, Salarrué, el hombre llamado a recoger el estandarte de los intelectuales salvadoreño [...] estamos frente a una política nueva. La política de la cultura" (Escobar, "Discurso del Director de la Biblioteca Nacional leído el 12 de noviembre en el acto inaugural de la exposición de libros", Boletín de la Biblioteca Nacional, noviembre de 1933). Escobar acuña un término muy en boga en el 2013 - "política de la cultura" - con el beneplácito del presidente y del intelectual.

En dicha revista, no sólo se anticipa la publicación del libro Cuentos de barro 
(1933) con los relatos "El negro", "El damo", "La botija" y "El Cheje", en demostración de un reconocimiento estatal a su narrativa. También se difunden juicios laudatorios oficiales sobre su obra, los cuales luego se repiten en nombre de lo popularsocialista, según se verá en seguida. En un acto público en la Universidad Nacional, se fragua la alianza entre los intelectuales, el masferreriano diario Patria, las autoridades universitarios y el gobierno. Se celebra un doble centenario: el de José Matías Delgado, prócer de la independencia salvadoreña, $\mathrm{y}$ el del escritor alemán Goethe (Centenario. Torneos universitarios, 1933; masferreriano refiere a Alberto Masferrer, el reformador idealista salvadoreño que propone un "mínimum vital" de vivienda, salud, educación y trabajo para todo ciudadano).

En la Universidad, las alocuciones se le dirigen al "Señor Presidente de la República, Señores Ministros del Estado, Señor Rector de la Universidad", como lo efectúa la conferencia de Francisco Gavidia, el máximo intelectual de la época. Mientras Gavidia certifica que en 1932, "la democratización de toda la América" significa que "el menor de los pueblos [...] como el José de la Biblia y como el David" El Salvador repite la gesta heroica de "la gran constituyen de 1824, los demás ponentes ratifican que la "obra" de los próceres "está en nosotros" (Centenario, 1933). Para renovar el pacto por la independencia nacional, se necesita la acción de "los hombres ilustres". Basta la presencia de un hombre providencial - uno de "los grandes conductores intelectuales de la humanidad" - cuyos atributos teosóficos resalten. La alusión a Salarrué resulta incontestable, ya que él es el único en inventar una Atlántida, como en 1932 se anhela forjar un país renovado.

No se trata de una nueva alianza del "soldado y el letrado", entre colegas teósofos quienes pertenecen a la misma Logia Teotl. Desde la década de los veinte el general - "lector de la filosofía indostana" - y el escritor - "entusiasta de la Teosofía" - comparten espacios intelectuales comunes (J. Gómez Campos, Semblanzas salvadoreñas (1930) y Revista Excelsior, 1928). Además, al igual que el general José Tomás Calderón, quien dirige la campaña militar contra los insurrectos en 1932, el general Martínez desempeña un alto cargo en la directiva del Ateneo de El Salvador, desde mediados de la década de los veinte, lo cual le concede un prestigio intelectual insospechado, antes de su nominación presidencial (Revista del Ateneo, 1920-1932).

La reseña de mayor relevancia política se intitula "Escritores salvadoreños Salarrué", escrita por Quino Caso, el teniente Joaquín Castro Canizález, miembro del "Directorio Militar" en diciembre de 1931, quien "controla los asuntos nacionales", incluso la literatura (Boletín de la Biblioteca Nacional, mayo de 1932). Su obra pictórica la ensalza Luis Alfredo Cáceres Madrid, "Salarrué colorista", quien se dedica a "culturizar la tropa" junto a su colega indigenista José Mejía Vides (Boletín de la Biblioteca Nacional, mayo de 1932).

Si la actividad pedagógica de Cáceres Madrid y Mejía Vides lleva a la práctica la propuesta de Cañas en "La hora del maestro" - "culturizar" y "nacionalizar al pueblo" para evitar el engaño comunistala difusión de los "cuentos de barro" desempeñaría el papel de inculcar un sentimiento nacionalista similar, por la lectura de temas campestres e indigenistas. "Ofrecen sus servicios [...] los Sres. Mejía Vides, Cáceres y Álvarez [...] en la modelación espiritual" del pueblo y en la "difusión cultural en los poblados" y "en la tropa para mejorar las condiciones materiales y espirituales de la clase 
proletaria" (La República, No. 68 y 84, $1^{\circ}$ de febrero y de marzo de 1933). El arte plástico indigenista de los mejores pintores se pone al servicio de la causa nacionalista y anti-comunista.

La "política del espíritu" requiere que los intelectuales se comprometan en desarrollar la nación por un "leer y escribir" según la consigna del pensador Alberto Masferrer, quien propone la alfabetización de las masas como un derecho humano fundamental. Hay que construir un canon literario y pictórico que exalte los valores nacionales. A los escritores y artistas les corresponde rescatar las tradiciones campesinas e indígenas para plasmarlas en el lienzo, en la poética y en la música. Tal es la solicitud que Cypactly. Tribuna del Pensamiento Libre de América les extiende a sus colaboradores, a los intelectuales teósofos.

Si sus contribuyentes son los "ungidos", la petición de Cypactly significa la formación de una cultura nacional arraigada en lo popular. "Francisco Gavidia, Salarrué... cuántos y cuántos, todos los ungidos, las almas luminosas de nuestra patria, ungen y consagran con sus plumas estilistas las páginas de Cypactly" (Lydia Valiente, Cypactly, 20 de marzo de 1932). Las figuras fundadoras de la literatura nacional salvadoreña colaboran en esa "tribuna del pensamiento libre de América" que legitima la matanza en nombre del antiimperialismo. La soberanía nacional autoriza la legítima defensa.

Los requisitos que Cypactly le impone al arte nacional equivalen a la exigencia política que solicitan los comprometidos décadas después. Se trata de la representación y recolección (Logos) de una cultura popular y democrática. Hay que prestarle "atención a las cosas nuestras para trasladarlas al libro, al lienzo, al pentagrama" reconociendo "la riqueza" que genera "la clase proletaria" (Cypactly, 10 de febrero y 10 de julio de 1932, nótese el uso de la terminología marxista que la reitera oficialmente La República. Suplemento del Diario Oficial).

En eco cercano a la "Mi respuesta a los patriotas", los intelectuales teósofos apoyan un gobierno neutral. Su obra no favorece a los "crueles comunistas pedigüeños" que "hablan de degollar" para imponer "la justicia", ni a los "capitalistas embrutecidos" que sólo piensan en "el mercado" (Repertorio Americano, febrero de 1932). Hacia 1932, se insinúa que el régimen del general Martínez establece un balance socialista radical entre "la tesis proletaria" del "trabajo como fuente de riqueza" y "la tesis burguesa" del "capital" en una "democracia integral" (La República. Suplemento del Diario Oficial, 1932 y Cypactly, 1932).

\section{II.}

$\mathrm{Si}$ "Mi respuesta a los patriotas" vindica "al indio del arado y la cuma", es porque "nada tiene" ni reclama. "Está satisfecho de hacer vivir" con su trabajo sin alzarse en armas como los "embrutecidos degolladores" que exaltan a la revuelta. El indio que trabaja para restaurar el orden tradicional -Juan Pashaca en "Cuento de barro. La botija" - se caracteriza por una actitud laboral muy distinta a la del "indio comunista" de 1932. No se lanza a un "levantamiento de venganza". Igualmente si "Mi respuesta a los patriotas" vindica a "la mujer soñadora", es porque carece de voto, del derecho político más elemental de una democracia electoral. Junto al "indio contemplativo", la fémina no hace política. "La política no sólo es infructuoso sino dañina" a quien la ejercita. 
Quizás por defender la pasividad vegetal, apolítica sublime, de los indígenas y las mujeres, "Mi respuesta a los patriotas" pasa desapercibida de todas las "Actividades literarias en el año de 1932" que reseña Juan Felipe Toruño en el Boletín de la Biblioteca Nacional (1934) y en la Revista del Ateneo de El Salvador (1932). En 1932, el único escritor salvadoreño que directamente denunciaría la "matanza" jamás la refiere como tal, ni sus colegas y contemporáneos lo perciben en oposición al gobierno. Como redactor de la revista de la Logia Teotl - a la cual pertenecen Salarrué, el general Martínez, etc. - Toruño desempeña el papel del intelectual orgánico, estrechamente ligado al ascenso y a la presidencia del general. Así lo testimonia el único escritor marxista estalinista - Miguel A. Ibarra en Cafetos en flor (1947) - cuya obra queda en el olvido. Por tal razón, para Toruño, la lectura de Salarrué -como un intelectual teósofo, colega y partidario de la misma causa política - resulta de un juicio contundente.

Al presente, el conocimiento generalizado de "Mi respuesta a los patriotas" no sólo sirve para rechazar la historia, es decir, para recordarla sin las otras fuentes primarias de 1932. Así se justifica borrar la recepción temprana que goza la obra de Salarrué en los círculos oficiales del martinato, según las revistas antes citadas. También, como única referencia, la "respuesta" oculta las otras actividades de Salarrué en ese año clave, las que rara vez se mencionan en la historiografía literaria. Nadie refiere las múltiples reseñas que recibe su indigenismo y fantasía - en literatura y en pintura - de sus contemporáneos y primeros espectadores. Ni menos aún se cita el compromiso tardío de Salarrué, quien al despegue del segundo mandato presidencial del general Martínez (1935) desempeña el cargo de "delegado oficial" a la Primera Exposición Centroamericana de Artes Plásticas en San José, Costa Rica, 1935 (Diario Oficial, septiembre de 1935; véase: Salarrué. El señor de los mares, 2007, que omite citar el evento artístico más connotado del istmo en los años treinta; véase también: la "Carta de agradecimiento del padre de Sandino a Maximiliano Hernández Martínez", "por su cooperación moral en pro de la justicia", La República. Suplemento del Diario Oficial, 12 de marzo de 1934).

La tesis que sustenta la falta de denuncia, la verifican otros lectores contemporáneos de Salarrué. Basta citar que su primer antólogo, Hugo Lindo (1969-1970), excluye la estrecha relación entre su narrativa y el 32; o que un crítico estadounidense de prestigio, Seymour Menton (1964), entrevea en "La botija" una burla socarrona de un campesino hecho payaso. Toda lectura temprana de Salarrué contradice la interpretación actual. No existe una obra sin lectores ni intérpretes contemporáneos, quienes jamás la perciben como una crítica social de la matanza.

No sólo ese aspecto histórico lo ignora la lectura generalizada de "Mi respuesta a los patriotas". La aburrida cita que se re-cita también se utiliza para descalificar todas las demás "actividades literarias [que] en el año de 1932" realiza Salarrué. Sirve de excusa para hacer historia sin historiografía. Ya se anotó la serie de cuentos y reseñas oficiales de 1932, las cuales demuestran que los juicios laudatorios sobre Salarrué los inician las revistas ligadas al régimen del general Martínez, antes que los repita la generación comprometida en la continuidad de su ruptura.

El propio Ítalo López Vallecillos quien acuña el término "generación comprometida" - honra a Salarrué por sus dotes poéticas y personales sin establecer un vínculo entre su obra y la política (La 
Pájara Pinta, septiembre de 1969). Más bien, podría fecharse de 1968 en la antología cubana que prologa Roque Dalton el considerar Cuentos de barro como "el testimonio global de la realidad campesina de El Salvador", "en un momento histórico de gran actividad político-social [...] la rebelión indígena de 1932". A Dalton lo refrenda el nicaragüense Sergio Ramírez en la antología venezolana (1977) por $\mathrm{su}$ "respuesta [de alivio] frente al clima [de etnocidio] creado por los ladinos". Después de ellos, José Roberto Cea (1986) califica a los pintores Cáceres Madrid y Mejía Vides "fiel[es] a la expresión nacional [...] en busca de la identidad" genuina. Todas estas reseñas críticas de la generación comprometida comparten un rasgo en común. Al convertir a Salarrué y al arte indigenista en artífices de su causa política no documentan el contexto histórico de su producción y recepción. La obra original queda desprovista del marco historiográfico de la década de los treinta.

A los cuentos de barro falta agregar la publicación de Remotando el Uluán, la única novela de Salarrué en 1932, su participación en los actos oficiales del Centenario de José Matías Delgado y de Goethe - referido anteriormente- junto a las autoridades gubernamentales y de la Universidad de El Salvador, al igual que la exhibición de "muñecas indígenas" que dan risa, junto a su esposa Zelie Lardé (Cypactly, 20 de marzo de 1932 y 22 de junio de 1932). Son "tan graciosos que hacen reír al más triste" (Cypactly, marzo y junio de 1932)

Si en Cypactly lo indígena hecho monigote es lo cómico y lo irrisorio - tal cual lo refrenda Menton años después- el Centenario de Matías Delgado y Goethe revalida el juicio de Castro Canizález quien hace de Salarrué el escritor cuya "labor intelectual" resulta precisa para refundar la nación luego de "imprevistos y fatales sucesos" (Centenario, 1933). Sólo un "alma solitaria y complicada" quien "como Platón" y "Goethe tiene su Atlántida" - podría encarnar una tarea tan "inquietante" como expresar el "espíritu sabio" de El Salvador. En "esta hora americana de profundas y trascendentales renovaciones" - según cita de León Trotsky - un "hombre y su pensamiento" nos salva: Salarrué (Centenario, 1933).

La única novela del autor en 1932 siempre se juzga como pura fantasía. Pero, sin asombro, la fantasía masculina por excelencia siempre se arraiga en el cuerpo sexuado de la mujer. El viaje astral del escritor místico lo propulsa una experiencia sexual con una "bella" afro-descendiente desnuda. La vivencia más espiritual del teósofo la estimula el apetito por la pródiga carne femenina.

"Abriendo aguas vírgenes [...] tras algunas caricias y mimos [en el] fumbultaje musical con Gnarda, perfectamente negra y perfectamente bella", Salarrué "remota el Uluán"; "encantador el viaje" de ingreso "a las nebrunas sensuales y a las alectaras sensitivas" de "la minería" femenina. "Se unieron nuestros labios y nos besamos [...] desde aquel día fue para mí doblemente encantador el viaje [...] habiendo llegado una mañana a [...] una abertura circular que tenía el aspecto de laguna".

La fantasía revela un aspecto étnico y de género acallado por el puritanismo crítico que no reconoce el cuerpo humano ni el deseo. El hombre blanco se deleita de su poder sexual sobre una "mujer negra". Bastaría cambiar el género de la cita precedente - Zelie Lardé fornicando con un "hombre negro" en el encanto de su "abertura circular" - para que la experiencia místico-sexual se vuelva escándalo. 
1932 se resuelve en la disparidad étnica y de género: hombre blanco vestido vs. mujer desnuda negra o de color como relación de clase. Si se prefiere, la lascivia del Conquistador se satisface en la desnudez de La Chingada, la primera comunista de América (Alemán Bolaños, 1944 y Machón Vilanova, 1948; en ambos autores la dirigente del Socorro Rojo Internacional es una indígena que sufre el abuso sexual del hombre blanco).
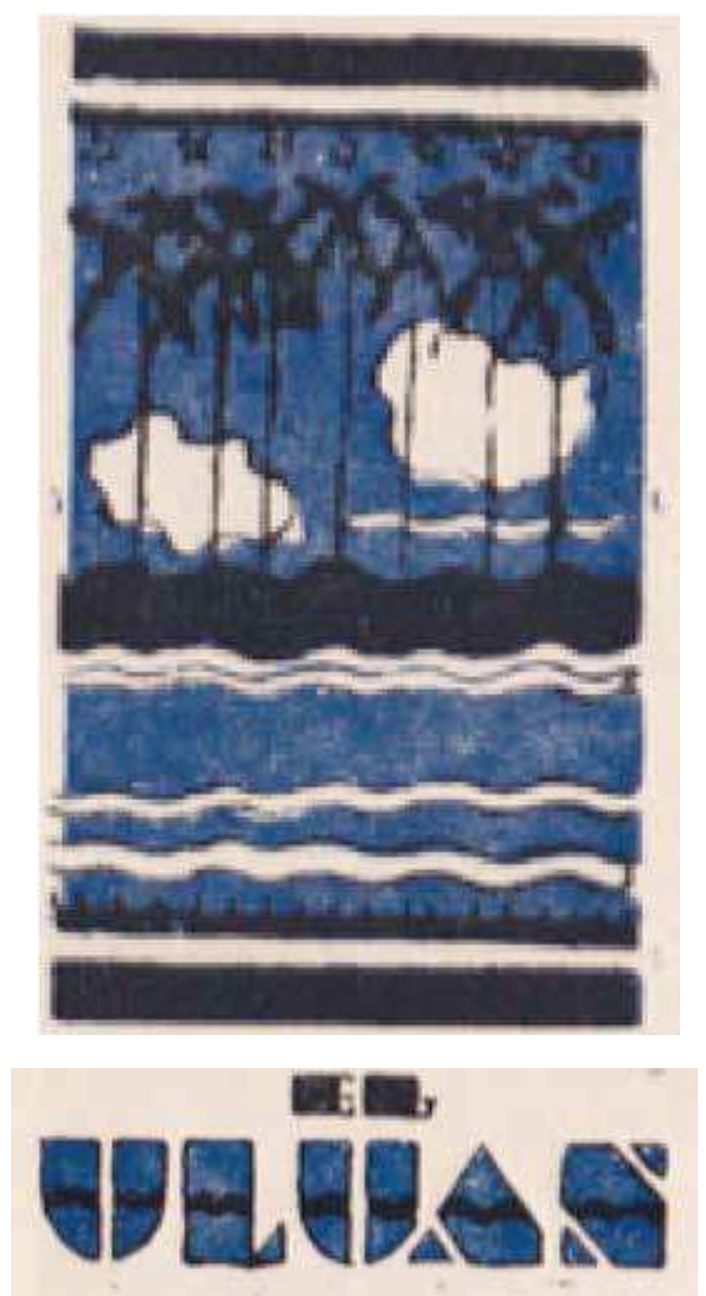

Viñeta de Remotando el Uluán (1932) la única novela corta de Salarrué, publicada en un año clave, pero excluida de todo comentario sobre los sucesos de 1932. El viaje astral reseña su relación étnico-sexual con Gnarda, una "bella mujer negra desnuda", y el encuentro con múltiples grupos étnicos en su mayoría femeninos, de colores exóticos, y de carácter sensual. Parecería que ocultar el trasfondo étnico y sexual de los asuntos sociales sería una manera de escribir la historia.
III.

Al presente, la categoría de memoria histórica se halla en boga en los estudios culturales ehistóricos.Sepresuponequeuna introspección personal - la anamnesisreemplazaría toda hipómnema o prueba de archivo. La memoria presente de los sujetos históricos bastaría como prueba de los hechos pasados. Tal imagen remeda lo que sucede en la Biblioteca Nacional de El Salvador. En los anaqueles, faltan casi todos los periódicos de 1932. El lugar de consignación de los archivos nacionales anticipa el vacío de la memoria actual. No habría más huella de la historia que el indicio interior. La marca en el recuerdo subjetivo de los agentes históricos sustituye las fuentes primarias de la época. Toda exterioridad queda anulada o reducida al mínimo.

La fórmula derridiana resulta pertinente. El archivo lo guarda "un lugar de autoridad (el arconte, el arkhefon, es decir, frecuentemente el Estado)". Al repudiar tal jurisdicción política -un estado militar y represivo- el lugar mismo de la consignación del archivo queda en entredicho. De este cuestionamiento se deriva una dislocación que separa la memora del archivo. No sólo sucede que las fuentes primarias de 1932 no se mencionen al hablar del 32. Ocurre que las referencias tardías se dictaminen con mayor rigor en evidencia de los sucesos ocurridos ese año clave.

Para el caso de Salarrué, una lectura de su denuncia tardía en Catleya luna (1974) suele reemplazar la inmediatez de un testimonio. Falta cuestionar cómo un recuerdo postrero enturbia el pasado. En la novela, una falsificación de los actores mismos del 32 - los indígenas Izalco - se sucede en una secuencia compleja. De imaginarlo 
como originario de la Atlántida, el autor culmina en la invención de etimología y de una mitología náhuatl-mexicana y quiché. La memoria histórica de Salarrué - el Sagatara mítico - sustituye todo archivo nacional de los náhuat-pipiles.

En primer lugar, en la "región de Tlapallan (La Tierra del Arco Iris) y a raíz del destronamiento de las dinastías aztecas, allá por el siglo XI, el gran Topilzin Axil funda y gobierna el Señorío de Cuzcatlán. Topilzin Axil, gran sacerdote y gran rey a la vez, volvía desde la tercera Tulán [...] a la primitiva Tulán del Güija, la semi legendaria, pues [el] origen de los Toltecas-Nahoas, existió en un Oriente que los historiadores (ignorantes de las fuentes iniciáticas) consideran mítico, cuando en verdad era el centro original Tolteca de la antigua Atlántida y los Toltecas (esparcidos por todo el mundo) sólo eran la tercera sub-raza de la cuarta raza humana, la raza atlante, de donde derivan todos los indios americanos" (Salarrué, 1974). Los errores históricos son crasos. $\mathrm{Al}$ origen atlante le prosigue el invento de una Tollan "primitiva" en el lago de Güija, que sustituye la del altiplano mexicano, la de pueblos aztecas dos siglos antes de su llegada a México, hasta culminar en la fantasía de un "Avatar" inmortal o Topiltzin, término que nombra un cargo político-religioso más que un personaje histórico. A la invención de un génesis náhuat-pipil se agrega la negación de la antropología moderna.

En segundo lugar, el logos indígena lo "proyecta" la actividad espiritual del artista en su trascendencia creadora. De su artificio innovador se derivan etimologías erróneas como "apuyeca" para Izalco que no significa "el hoyo de los vientos" (Salarrué), sino "agua (at) caliente o salada (puyek)". Teshcalán tampoco significa "piedra de sacrificios", sino el náhuatl- mexicano Texcallan designa una «localidad tlaxcalteca (Tlaxcallan), de tlaxcalli, "roca, elevación..." y tlan, "locativo"», etc. (Rémi Siméon, 1977 y Campbell, 1986). Un mínimo cotejo de los sentidos de las palabras en Salarrué con diccionarios autorizados demuestra la ficción del recuerdo.

En tercer lugar, el autor autoriza fabricar una mitología náhuat-pipil que, sin prueba en los archivos, se reconoce fiel a un legado ancestral (Salarrué. El señor de los mares, 2006). Las lecturas de fuentes náhuatlmexicanas y quiché-guatemaltecas testimonian de la "tragedia de los Izalco". La cosmogonía náhuat-pipil, el autor la calca del altiplano central mexicano. Por tal razón, aparece la " $\mathrm{tl}$ " en una lengua que carece de tal sonido. A falta de documentos náhuat-pipiles, la evidencia náhuatl-mexicana llena el vacío en la memoria de Salarrué. Figuran "Tlaloc y Chalchiutlicueye" en el "Tlalocán", al igual que los "Cenzón-Huitznahuas" en el Mictlán", Quetzalcoatl, Tezcatlipoca, Camaxtli (deidad tlaxcalteca), etc. (ojo: no se corrigen los errores ortográficos del autor que saltan a la vista). El panteón lo completan el yucateco "Itzama", confundido con la chichimeca "Itzpapalotl", de Cuauahtitlán, los quichés "Kukulcán" y "Kabrakán", al igual que el muisca Bochica, etc. (Salarrué, 1974). No hay una sola divinidad náhuat-pipil que enmarque la revuelta de 1932 en la memoria salarrueriana.

Ya no hay un archivo nacional en su lugar de consignación, sino que la Biblioteca Nacional existe al interior mismo del sujeto que escribe. Tal abolición la legitima la "busca de mí mismo", ya que el otro, el indígena náhuat-pipil, se revierte sobre la subjetividad del autor. Por el otro, "emprendí anhelosamente el camino hacia mi propio centro" (Salarrué, 1974). En imitación de uno de los padres 
fundadores del canon literario nacional, la historiografía literaria salvadoreña repite su consigna. Los archivos del pasado son secundarios, ante la memoria histórica que nos define en nuestra identidad actual, en crisis por una disgregación transnacional.

\section{Referencias Bibliográficas}

Alemán Bolaños, Gustavo. El oso ruso, historia novelada del primer movimiento comunista de América. Nicaragua: Editorial Atlántica, 1944.

Alvarenga, Patricia. Cultura y ética de la Violencia: El Salvador, 1880-1932. San José: EDUCA, 1996.

Boletín de la Biblioteca Nacional. 19321944.

Campbell, Lyle. The Pipil Language of El Salvador. The Hague: Mouton Pub., 1986.

Cea, José Roberto. La pintura en El Salvador. San Salvador: Editorial Universitaria/Canoa Editores, 1986.

“Centenario de José Matías Delgado y Goethe". Torneos universitarios. San Salvador: Publicaciones de la Universidad de El Salvador, 1933.

Cypactly. Tribuna del Pensamiento Libre de América. 1931-1944.

Derrida, Jacques. www.jacquesderrida. com.ar.

Diario Oficial. 1932-1935.

Espino, Miguel Ángel. Obra narrativa. San Salvador: Dirección de Publicaciones e Impresos, 2007. Recopilación, estudio crítico y notas de Luis Alvarenga.
Gómez Campos, José. Semblanzas salvadoreñas. San Salvador: Talleres Gráficos Cisneros, 1930.

Gould, Jeffrey y Aldo Lauria-Santiago. To Rise in Darkness. Durham, NC: Duke U. P., 2008.

Ibarra, Miguel A. Cafetos en flor. México, D. F.: Sin Editorial, 1947.

La Pájara Pinta, 1969.

La República. Suplemento del Diario Oficial. 1932-1944.

La Universidad. Órgano de la Universidad Autónoma de El Salvador. No. 2, 1937.

Lindo-Fuentes, Héctor, Erik Ching, Rafael Lara Martínez. Remembering a Massacre in El Salvador: The Insurrection of 1932, Roque Dalton, and the Politics of Historical Memory. Albuquerque, N. M.: U. of N. M. P., 2007.

Machón Vilanova, Francisco. Ola roja. México, D. F.: Sin Editorial, 1948.

Menton, Seymour. El cuento hispanoamericano. México, D. F.: Fondo de Cultura Económica, 1964.

Pérez-Brignoli, Héctor. "La rebelión campesina de 1932 en El Salvador". En: Thomas Anderson (ed.), 1932. Los sucesos políticos. San Salvador: Concultura, 2001:17-54.

Siméon, Rémy. Diccionario de la lengua náhuatl o mexicana. México, D. F.: Siglo XXI Editores, 1977.

Repertorio Americano. 1932-1935.

Revista Excelsior. 1928-1930.

Revista del Ateneo de El Salvador. 19201932. 
Revista del Ministerio de Instrucción Pública. 1942.

Sáenz, Vicente. Rompiendo cadenas, las del imperialismo yanqui en Centroamérica. México, D. F.: Editoral Ciade, 1933. Las ediciones posteriores suelen tachar el apoyo inicial del socialista costarricense al general Martínez

Salarrué. Remotando el Uluán. San Salvador: Agua y Arena, 1932.

Cuentos de barro. San Salvador: Editorial "La Montaña", 1933. Viñetas de José Mejía Vides. La edición príncipe sólo incluye treinta y tres cuentos, dos tercios del total. Tampoco contiene las ilustraciones originales incluidas en las revistas de la época. "El mal de archivo" ocasiona que, a ochenta años de su publicación, aún no exista una edición completa de uno de los libros emblemáticos del canon nacional.

Cuentos. La Habana: Casa de la Américas, 1968. Prólogo de Roque Dalton.

Obra escogida. San Salvador: Editorial Universitaria, 1969-1970. Hugo Lindo (Introducción y Editor).

El ángel en el espejo. Caracas: Editorial Ayacucho, 1977. Selección y prólogo de Sergio Ramírez.

Catleya Luna. San Salvador: Dirección de Publicaciones del Ministerio de Cultura, 1974.

Obra narrativa completa. San Salvador: Dirección de Publicaciones e Impresos, 1999. Prólogo, compilación y notas de Ricardo Roque Baldovinos.

Salarrué, el último señor de los mares. San Salvador: Asociación Museo de Arte de El Salvador, 2006. Texto principal de Ricardo Lindo; Cronología de Ricardo Roque Baldovinos.

"Los que no entendemos. El sentido común". Sin Editorial ni fecha. Cortesía de Ricardo Aguilar.

Tilley, Virginia. Seeing Indians. Albuquerque, NM: U. of NM P., 2005.

\section{Apéndice}

CONTRA EL EXPRESIDENTE ARAUJO

(Diario Latino, 10 de diciembre de 1931)

Interesante hoja suelta que circuló en Guatemala firmada por Alberto Masferrer, Adolfo Pérez M, y Serafín Quiteño.

En las declaraciones categóricas que el presidente don Arturo Araujo ha hecho a los diarios de esta capital (Guatemala) y en los declaraciones complementarias que han hecho a las entusiasmadas personas que le acompañaron en su fuga se ve con claridad que llega a la evidencia, que su único pensamiento, su único propósito fue pone en manos del gobierno de Washington la solución del conflicto que ha estallado entre él y el pueblo salvadoreño.

Antes de releer la extraordinaria e inolvidable declaración del señor Araujo, conviene rememorar los episodios sobresalientes de esta debacle.

El dos de ese mes (02DIC931) en la noche, estalló el movimiento para derrocar al señor Araujo.

Un cuarto de hora después, el señor Araujo abandonó la capital, siguiendo para Santa Tecla, y de ahí a Sonsonate, Ahuachapán y Santa Ana. Eso suma un trayecto de más de cuarenta leguas, recorrido desde 
noche, lo cual no impidió (nos atenemos estrictamente al, contenido de las declaraciones) que en todos esos lugares se le hicieran entusiastas y nunca vistas ovaciones.

Si es verdad que siguieran tan extraña, larga e innecesaria ruta, el señor Araujo y sus acompañantes no han podido llegar a Santa Ana, en las pocas horas que ahí permaneció, pidió consejo al vecindario, y tanto civiles como militares opinaron que (sin negarle, naturalmente, su carácter de Presidente) lo mejor era que continuara su viaje a Guatemala, de donde podría regresar cuando se hubiera terminado la cosecha del café. Es decir, incluyendo la corta, el beneficio y el embarque, de aquí a principios de marzo. El día cinco a las once, llegaron a Guatemala, donde el primer cuidado del señor Araujo, fue pedir por cable el auxilio de Washington. Ya veremos en qué términos.

En Santa Ana, inmediatamente de la llegada del señor Araujo, se organizó un gran ejército, que se puso a la defensa del presidente.

El Presidente, por humanidad, y para no estorbar la cosecha del café, no quiso hacer uso de ese ejército, ni de los grandes recursos que el país pondría en sus manos, a juzgar por las extraordinarias ovaciones que se le hicieron durante su velocísima carrera. Lógico es aceptar que el doctor Olano, Tercer Designado a la Presidencia y Delegado del Señor Araujo a quién este entregó el Gobierno se inspirara en las mismos sentimientos de humanidad y de respeto a la cosecha de café y no querrá el tampoco hacer uso del grande ejército que se organizó en defensa del Presidente Araujo. Si el doctor Olano hiciera lo contrario, faltaría a las intenciones y propósitos del Presidente que delegó en él su poder.
Estamos, pues, en una situación curiosísima, inédita, única hasta hoy en la historia de El Salvador un gobernante constitucional popularísimo, ovacionado como nunca, recibido entusiastamente en una plaza de tantos recursos como Santa Ana, disponiendo de un gran ejército y de la adhesión fervorosa de civiles y militares, seguro de que todo el país está con él - y quien, ante un puñado de rebeldes, no encuentra mejor recurso que salir del país, en una carrera casi vertiginosa, llega a la capital de Guatemala y - a pedir socorro a Washington.

Que el lector, si fuere medianamente reflexivo, enlace entre si los episodios historiados. (léase El Imparcial del cinco del corriente), que trate de relacionarlos con las causas verosímiles; que recuerde la historia y la índole de los salvadoreños; que piense unos minutos en la psicología de las revoluciones y rebeliones en Centroamérica, y en la manera usual: y obligada de combatirlas, y que vea si da con la solución del enigma. No estará demás, para acertar mejor y más pronto, advertir que el único miembro del Gobierno de acompaña al señor Araujo, es el Subsecretario de Gobernación, y el único militar, el Director de Policía. Aparte de ellos - y no adivina uno por qué ni para qué. El Director de la Penitenciaría y el Director de Correos. No se puede viajar menos acompañado. Olvidábamos al Secretario Particular y al Jefe de Protocolo. No se necesita ser un lince político para adivinar las causas de lo sucedido ni para comprender la verdadera e irremediable situación del señor Araujo. La palabra Debacle, deshielo violento, encierra la explicación del drama. Eso es lo que hay: en sólo nueve meses, el Presidente Araujo perdió la grandísima popularidad de que gozaba; el prestigio de una elección libre, en la cual, ciento cinco mil votos le dieron el triunfo más resonante y decisivo. Todo 
lo perdió el señor Araujo en nueve meses apenas.

Es decir que a los nueve meses estalla el movimiento que lo ha derribado en pocas horas su desprestigio, la decepción profunda que ocasionó al país con su sistema y su criterio de gobierno, y el consiguiente y fuerte anhelo de quitarse de él, fueron cosa de cuatro meses a los sumo. Virtualmente, en la realidad correcta de las cosas, el señor Araujo ya no es Presidente de El Salvador y le ha despedido como a un servidor inútil y estorboso. Tanto es así que acude al único y tristísimo recurso de poner en manos del Gobierno de Washington. Este mísero y repugnante arbitrio a que los gobernantes desacreditados tras de largas y oprobiosas tiranías acuden en último término, ha sido para don Arturo Araujo el primero, el mejor y el único. No se le ocurrió otra cosa... porque no contaba con otra cosa.

Véase, en comprobación, lo que declaró a los diarios de esta ciudad, y cuyo texto reproducimos de El Imparcial del cinco de este mes: "Espero que el departamento de Estado de Estados Unidos decida su apoyo al Delegado de mi gobierno, Doctor Olano, de acuerdo con el espíritu de la legalidad que siempre ha sido norma en el gran pueblo del Norte, y tan pronto como ello ocurra, yo regresaré a mi país a ponerme al frente de sus destinos, que ahora y siempre me fueron tan caros".

Es decir, tan pronto como el Departamento de Estado envié marinos americanos don
Arturo Araujo volverá a El Salvadora a asumir sus funciones de Presidente. Se ve que el señor Araujo ni siquiera llega a conocer la patología de su país en lo que tiene de más somero y bien puesto (?) que en su repugnancia invencible a que lo gobiernen los extraños. Se engañó esta vez, como siempre: una simple nota de Washington, no bastará para que los salvadoreños consientan de nuevo en el gobierno a don Arturo Araujo. Sería indispensable la presencia de los marinos y solo haber pensado en ellos, el expresidente Araujo se ha enajenado, seguramente, las escasas simpatías que aún pudieran quedarle.

Sean quienes fueren los que han asumido el poder en El Salvador, nosotros los aceptamos desde ahora, y les prestamos nuestra adhesión, por habernos desembarazado de un hombre que con tanta facilidad acude a la intervención de un poder extraño, que ningún derecho tiene para dirimir nuestras contiendas.

Don Arturo haría bien en renunciar ya su cargo de Presidente. Sería un servicio al país, y quizá bastaría para que sus buenas intenciones levantaran un poco en la balanza el platillo abrumado ahora bajo el peso de sus muchos y enormes errores. Guatemala, 6 de diciembre de 1931Alberto Masferrer, Adolfo Pérez M., Serafín Quiteño.

Cortesía de Caralvá a quien le agradezco el envío. 